\title{
Introdução à História do Direito Japonês"
}

\author{
Yuko Nishitani ${ }^{1}$ \\ Professora de Direito Internacional Privado da \\ Universidade Tohoku, Sendai, Japão \\ Mestre em Direito pela Universiadde de Kyoto, Japão \\ Doutora em Direito pela Universidade de Heidelberg, \\ Alemanha
}

Sumário: 1. A história do direito japonês. $-a) \bigcirc$ período antigo. $-b)$ O período feudal. - c) A recepção do direito ocidental. - d) Depois da Segunda Guerra Mundial. -2. As características do ordenamento jurídico japonês.

1. A história do direito japonês

a) O período antigo

Conhecemos a situação política do Japão do século I ao III graças a algumas documentações encontradas na China, onde os japoneses, considerando-se a superioridade política e econômica da China, enviavam regularmente as delegações com ofertas ao imperador: escravos, arroz e tecidos. Os documentos japoneses autênticos referem que, não muito depois do século IV, os reis (em seguida chamados "tennô" = imperadores) começarão a unificar e a dominar muitas partes do Japão, que antes se encontravam sob a hegemonia de clãs poderosos. Esses reis justificavam o seu poder apoiandose no shintoismo, isto é, na religião japonesa, na qual o rei vem considerado como um dos dei e o filho da deusa do sol Amaterasu.

\footnotetext{
"Este artigo baseia-se no seminário proferido na Università Statale di Milano em 06 de março de 2000, durante a minha permanência na Itália. Queria agradecer a professora Gigliola di Renzo Villata e o professor Antonio Padoa Schioppa por terem me dado a oportunidade de falar sobre a história do direito japonês no âmbito dos cursos por eles mantidos e por terem organizado a publicação na Itália.

1 Tradução livre autorizada de Maitê Schmidtz (Grupo de Pesquisa CNPq "Mercosul e Direito do consumidor"/UFRGS, bolsista Propesq/UFRGS), primeira revisão de Luciana Quinto (Grupo de Pesquisa CNPq "Mercosul e Direito do consumidor"(UFRGS,), revisão final de Profa. Dra. Cláudia Lima Marques,UFRGS.
} 
A forma do Estado foi completada no século VII (principalmente após a revolução de taika em 645) tomando como base a instituição chinesa. Na China, onde florescia a alta cultura da dinastia de Tang (618-), a codificação acontece sob a influência do confucionismo e dos legalistas: em particular vêm redigir o código administrativo (ling) e o código penal (lü), junto com o agrupamento dos decretos provisórios (ge) e das normas

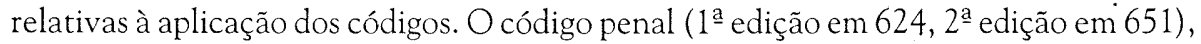
para excluir a possibilidade de uma repressão penal arbitrária, continha um elenco de 445 figuras de crimes e das penas correspondentes; foi prevista também a diminuição da pena em razão do status social e do sexo do réu, da modalidade de execução do crime, dos motivos do réu, etc. ${ }^{2}$ Esse código penal foi tão avançado a ponto de não ser completamente inferior à Constitutio Criminalis Carolina de $1532^{3}$, promulgada cerca de novecentos anos depois ${ }^{4}$. Com base nesses códigos chineses, o imperador japonês promulgou o código penal (ritsu) e o código administrativo (ryô) em diversas edições 5 . O código penal baseou-se quase textualmente na lei chinesa, enquanto o código administrativo, que regulava a ordem dos funcionários e dos monges, o pagamentos dos impostos, o sistema do exército, etc, refletia a tradição japonesa. Os especialistas, com um amplo conhecimento do sistema ritsuryô, eram formados numa escola especial. Para unificar as diversas interpretações entre os juristas foram redigidos os comentários, com centenas de volumes já na metade do século IX ${ }^{6}$.

É de se notar que o problema típico derivado da recepção de um ordenamento jurídico estrangeiro, isto é, a contradição entre o direito recepcionado e o direito tradicional, já se mostrava nesse período. Por exemplo, ao invés da linha genealógica masculina utilizada na China, no Japão dominava, naquela época, a linha feminina; portanto, presume-se que, em contraste com o texto da lei, o divórcio fosse executado, em muitos casos, segundo os costumes japoneses, através do "repúdio do marido" e não segundo o dado normativo escrito, isto é, através do repúdio da esposa. Pode-se, assim, observar como nesse sentido

\footnotetext{
2 A. GAMBARO - R. SACCO, Sistemi giuridici comparati, in Trattato di diritto comparato da R. SACCO, Torino 1996, p. 511. Por exemplo, o crime de ataque e lesões foi subdividido em quatro categorias segundo os meios (com a mão ou o pé, com a água fervente ou o fogo, com a espada ou a faca, com um outro objeto) e em outras categorias segundo os resultados (a ferida e o puxão dos cabelos, a hemorragia nos olhos e nas orelhas, o sangramento da boca, a perda dos dentes, etc.). ÔTAKE - MAKI, Nihon hôseishi, Tokyo 1975, pp. 70 ss.

${ }^{3}$ Veja A. CAVANNA, Storia del diritto moderno in Europa, Milano 1982, p. 463.

${ }^{4}$ OTTAKE - MAKI, op. cit. (1), pp. 22 ss. No início o procedimento penal deveria instaurar-se sempre com uma denúncia dos funcionários ou dos particulares que arriscavam, por sua vez, serem acusados de difamação. O funcionário chamado a julgar a causa devia recolher as provas segundo o principio do livre convencimento e, se as provas não foram suficientes, colocava o acusado na tortura (paridade das partes). Se o acusado não confessasse, era torturado o acusador para verificar a inexistência da difamação. A apelação era prevista junto ao tribunal colegial de dajoukan. Porém, no curso do tempo, o princípio da denúncia foi substituido pelo aquele da inquisição e a apelação foi abolida para simplificar o processo. ÔTAKE - MAKI, op. cit. (1), pp. 90 ss.

${ }^{5}$ O taihô ritsuryô de 701 e o yôrô ritsuryô que foi reunido em 718 e entrou em vigor em 757 . Veja MARUTSCHKE, Einführung in das japanische Recht, München 1999, pp. 2 ss.

${ }^{6}$ Maki - Fujiwara, Nihon hôseihi, Tokyo 1993, pp. 32 ss.; Oda, Japanese Law, 2." ed., London/ Dublin/Edinburgh 1999, pp. 12 ss.
} 
prevaleceram os costumes japoneses sobre a norma escrita ${ }^{7}$. Embora o ritsuryô tivesse formalmente ficado em vigor até a metade do século XIX, perdeu pouco a pouco a sua real eficácia ${ }^{8}$.

b) O período feudal

O nosso feudalismo começou em 1192 e durou até 1868. Esse sistema político foi fundado no shôgun, o chefe militar. Ainda que o shôgun devesse ser formalmente nomeado pelo imperador, este não tinha praticamente mais nenhum poder político. A relação feudal baseava-se sobre o serviço dos vassalos ("samurai") e sobre a recompensa dos senhores, através da concessão da posse dos feudos, da carica (carga/função) pública e do domínio sobre o campo de arroz, sobre os quais vinham as cobranças dos impostos. Muitos estudiosos definem essa relação como "benevolente" e "moral", em vez de "contratual", como na Europa, e evidenciam como os feudatários não eram obrigados a uma contraprestação em direção aos vassalos 9 .

Na primeira metade do período feudal (era de kamakura e de muromachi) desenvolvem-se os costumes que faziam frente às exigências do sistema feudal e derrogavam o regulamento do ritsuryô, emanado do imperador e sustentado pela aristocracia. Durante o regime feudal da kamakura, em 1231, foi formado, por iniciativa do shôgun, um código com 51 artigos (goseibai shikimoku), recolhendo os costumes dos samurai e os precedentes judiciários. Nesse código destaca-se a exigência de julgar conforme a "razão", isto é, o costume dos samurai anotados, precedendo às leis escritas 10. Todavia, o shôgun e, depois da sua perda de poder a partir da segunda metade do século XV, os feudatários particulares independentes promulgarão as leis que disciplinavam a relação entre o senhor e os vassalos, a aquisição dos feudos, as relações familiares dos vassalos, etc. Essas leis, porém, não foram sistemáticas como ritsuryô, mas só específicas e parciais, de modo que a maior parte do "direito" existia sob forma de costume ${ }^{11}$. A importância dos costumes continuou na segunda metade do período feudal, a era edo (1603-), ainda que o shôgun dessa época tenha promulgado algumas leis importantes (por exemplo, buke shohatto e kinchî kuge-shohatto, em 1615; kujikataosadamegaki, em 1742, que foi redigido com base em atenta análise das leis e dos precedentes

\footnotetext{
${ }^{7}$ Ôtake - Maki, op. cit. (1), pp. 54 ss., 81 ss.

${ }^{8}$ Marutschke, op. cit. (4), p. 23.

${ }^{9}$ Murakami, Hô no rekishi, Tokyo 1997, pp. 16 ss. Alguns estudiosos, ao contrário, destacam o elemento "contratual" ou "sinalagmático" dessa relação feudal. Veja Ôtake - Maki, op. cit. (1), p. 112.

${ }^{10}$ Maki - Fujiwara, op. cit. (5), pp. 126 ss. O título do domínio sobre os feudos se chamava "chigyô". Com base no "chigyô" os feudatários podiam fazer valer o ius excludenti; eram previstos, também, o usucapião e a prescrição. Na doutrina japonesa encontram-se ainda hoje diversas opiniões sobre os caráteres do "chigyô"; alguns o caracterizam como o "Gewere" alemão da ldade Média, que não foi separado do conceito de propriedade, enquanto outros o concebem como a "possessio" do direito romano. Ôtake - Maki, op. cit. (1), pp. 130 ss. As causas sobre "chigyô" tiveram uma tal importância que foi fundado um processo especial. O processo penal se baseava na inquisição. As leis penais tiveram a finalidade de manter a ordem feudal e a segurança social em vez de disciplinar os crimes e as penas para eliminar a repressão penal arbitrária como o ritsu. Ôtake Maki, op. cit. (1), pp. 149 ss.
} 
judiciais, mormente em matéria penal ${ }^{12}$ ) e as associações particulares como as prefeituras, as cidades, os templos, os gilde tinham algumas regras próprias.

Durante todo o período feudal, a influência da China não foi muito decisiva, mas a parte principal do ordenamento jurídico japonês permaneceu sempre o direito penal e administrativo, como no ritsuryô. Na era edo desenvolviam-se também as causas privadas, principalmente sobre os mútuos. Mas o governo entendia que, as controvérsias pecuniárias deveriam ser resolvidas entre os particulares sem 'perturbar' os tribunais, que eram, nessa época, ainda órgãos administrativos do governo. Tanto é verdade, que o próprio governo promulgou, por onze vezes, em duzentos anos, medidas segundo as quais aos cidadãos particulares não era permitido ajuizar causas sobre mútuos (aitai-sumashi rei) ${ }^{13}$. Desse modo, desenvolveram-se, forçosamente, meios alternativos, como a conciliação ou a arbitragem, para resolver os conflitos entre os particulares.

c) A recepção do direito ocidental

No final da era edo, em 1853, quatro navios americanos chegaram de surpresa no Japão. Certamente já havia muitos ocidentais no Japão antes daquela época: os primeiros foram portugueses, que chegaram em 1543 e transmitiram a técnica da espingarda; após, em 1549, chegaram os missionários jesuítas para evangelizar os japoneses em plena contrareforma. Porém, a partir de 1633, o regime feudal edo, com medo de uma invasão, rejeitou o contato com os Estados estrangeiros - com exceção da China e dos Países Baixos -, até 1853, quando chegaram os americanos. O Japão cedeu ao pedido dos americanos de abrir os portos e concluiu Tratados "não paritários" em 1858 com os Estados Unidos, e após com o Reino Unido, a Rússia, a França e os Países Baixos. Segundo essas convenções, o Japão devia admitir a jurisdição extraterritorial do cônsul e renunciar ao direito exclusivo de fixar os impostos. Após a revolução de meiji, em 1868, através da qual o imperador retomou nas mãos o poder político, o governo japonês esforçou-se para ab-rogar estes tratados não paritários. Para atingir essa meta era necessário "modernizar" completamente o sistema jurídico, de modo que os Estados estrangeiros, negociando com os japoneses, estivessem seguros que os litígios entre os particulares fossem julgados num tribunal moderno, por um juiz que aplicasse normas jurídicas certas e sistemáticas ${ }^{14}$. Assim, começou-se a recepcionar, apressadamente, o sistema jurídico ocidental. Foram convidados professores de Direito, ou da França ou da Alemanha, e foram mandados alguns juristas japoneses ao exterior.

O Código Penal de 1880 foi redigido por Boissonade, um professor francês que se fixou no Japão entre 1873 e 1895, com base no direito francês e considerando a doutrina alemã; o artigo 2 declarava a "legalidade das penas", isto é, o princípio enunciado no artigo 8 da "Déclaration des droits de l'homme et du citoyen" de 1789, e abolia, fundando-se na igualdade dos indivíduos, quase todas as distinções dos crimes segundo o status social do réu. O Código Penal foi reformado em 1907, com a introdução, sob a influência da doutrina alemã, dos conceitos do subjetivismo e do finalismo das penas; esse código está, com algumas modificações, ainda hoje em vigor ${ }^{15}$. O Código de Processo Penal de 1880 , que

\footnotetext{
11 Ôtake/Maki, op. cit. (1), pp. 154 ss.

12 Os processos penais se baseavam, ainda, na inquisição. ÔTAKE - MAKI, op. cit. (1), pp. 232 ss.

${ }^{13}$ OKI, Nihonjin no hôkannen, Tokyo, 1983, pp. 158 ss. (principalmente pp. 188 ss.).

${ }^{14}$ HOSHINO, Minpô no susume. Tokyo, 1998, p. 194.
} 
continha ainda elementos processuais inquisidores, foi preparado por Boissonade e entrou em vigor em 1882. Foi, porém, reformado já em 1890, em conformidade com a lei sobre ordenamento judiciário de 1890, que tomou como modelo a lei alemã; também o Código de Processo Civil de 1890 foi recebido da Alemanha ${ }^{16}$. Essa orientação a favor do direito alemão foi reforçada com a promulgação da Constituição japonesa de 1889, que se baseava substancialmente na Constituição alemã.

A Constituição japonesa tomou aquela alemã como modelo porque a forma de Estado alemã, na qual o imperador (Kaiser) tinha fortes poderes com relação ao parlamento, parecia ajustada ao império japonês ${ }^{17}$. Segundo a Constituição japonesa, promulgada pelo próprio imperador, toda a soberania era concentrada em suas mãos, mesmo se fossem fundados diversos órgãos modernos do Estado ${ }^{18}$. $\mathrm{O}$ "governo" era colocado sob o controle do Conselho da Coroa (sûmitsu-in), e os poderes do parlamento eram limitados seja sob o ponto de vista da legislação (a aprovação do governo era necessária), seja sob o ponto de vista da redação e do reconhecimento do orçamento (a aprovação do governo era necessária). Também a autoridade de comando supremo das forças armadas pertencia ao imperador; por isso discutiu-se, depois da segunda guerra mundial, se o imperador era responsável pelo conflito ${ }^{19}$.

No que concerne ao Código Civil Japonês, os artigos com relações patrimoniais foram redigidos por Boissonade, segundo o modelo de Código Civil Francês, e o resto, sobretudo a parte sobre as pessoas e sobre a família, foi preparada por "funcionários" japoneses; o Código Civil Japonês foi promulgado em 1890 e a entrada em vigor foi prevista

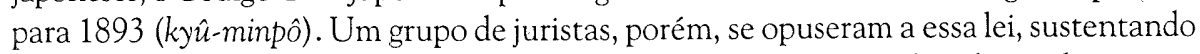
que tinha sido redigida com pressa, sem levar em consideração a legislação dos outros Estados modernos e que se baseava de modo oportuno no liberalismo e na igualdade dos indivíduos, destruindo, assim, a ordem econômica japonesa constituída sobre a produção coletiva. Esses juristas afirmavam ainda que a parte sobre as pessoas e sobre-a família se baseava no individualismo e não correspondia à tradição japonesa. Essa disputa sobre a codificação (Kodifikationsstreit) refletia, na realidade, a disputa entre os juristas da escola francesa e os da escola inglesa no Japão, isto é, entre os naturalistas e os historicistas. No fim, em 1892, o parlamento decidiu adiar a entrada em vigor do Código Civil, junto com a do Código Comercial de 1890 elaborado por um professora alemão, Roesler ${ }^{20}$, e sob o pretexto de modificá-lo foi redigido "por Nobushige Hozumi, Masaaki Tomii e Kenjirô Ume, um projeto inteiramente novo ${ }^{21}$.

\footnotetext{
15 ÔTAKE - MAKI, op. cit. (1), pp. 280 ss.

${ }_{16} \mathrm{O}$ código do ordenamento judiciário e o código de processo civil foram obra de Techow e de Rudorff, com base no Gerichtsverfassungsgesetz e no Zivilprozeßordnung. Veja MARUTSCHKE, op. cit. (4), p. 37.

17 Hirofumi Ito, que conduziu pesquisas sobre as constituições de vários paises europeus para preparar a codificação, estudou com Rudolf von Gneist em Berlim e com Lorenz von Stein em Viena e propôs a recepção da constituição prussiana com base na "doutrina do Estado" (Staatslehre) alemã e austriaca. MAKI - FUJIWARA, op. cit. (5), pp. 330 ss.

18 OTAKE - MAKI, op. cit. (1), pp. 286 ss.

19 IGARASHI, Einführung in das japanische Recht, Darmstadt 1990, pp. 18 ss.

20 O Código Comercial foi promulgado em 1890 e a sua entrada em vigor foi prevista para 1891. ÔTAKE - MAKI, op. cit. (1), pp. 291 ss.
} 
O sistema escolhido não foi mais aquele das institutiones do Código Civil Japonês de 1890, mas aquele pandetístico, próprio do Código Civil da Saxônia e sucessivamente também do BGB-Código Civil Alemão de 1896 (BGB). O sistema pandetístico, que previa uma subdivisão em cinco livros (parte geral, das obrigações, dos bens, da família e das sucessões), tinha o mérito de colocar as normas sobre as pessoas no livro I, separado das regras sobre a família; o "sistema da família ou sistema de casas", de fato, que refletià os costumes japoneses, foi colocado no início do livro IV, e não no capítulo 13 do livro das pessoas e da família, como no Código Civil Japonês de 1890. Desse modo, os primeiros três livros recepcionavam as instituições jurídicas européias modernas, enquanto os livros sobre a família e sobre sucessões refletiam a tradição japonesa ${ }^{22}$. Aprovado pelo parlamento em 1896 (a parte sobre relações patrimoniais) e em 1898 (a parte sobre família e sucessões), o Código Civil Japonês entrou em vigor em 16 de julho de $1898^{23}$.

A parte sobre as relações patrimoniais, que ainda está em vigor, levava em consideração não apenas os projetos do BGB, mas também as legislações de quase trinta países e a jurisprudência da Inglaterra e dos Estados Unidos ${ }^{24}$. Porém, em verdade, quase a metade das normas sobre relações patrimoniais do projeto permanecia baseada no Código Civil Francês, como o projeto preliminar de Boissonade. Esse fato se observa hoje sobretudo no direito das coisas. Nós não temos o princípio da abstração (Abstraktionsprinzip), mas o princípio consensualístico (Konsensualprinzip); temos institutos que não existem no BGB, como os privilégios (Vorzugsrecht) e a ação sub-rogatória (Gläubigersurrogation). Não obstante, como muitos estudiosos indicam, praticamente recepcionamos grande parte da doutrina do direito alemão através dos processos de interpretação e de aplicação das normas. Por exemplo, a "culpa in contrahendo" foi introduzida no Japão seguindo a doutrina de Jhering. No que concerne, após, ao inadimplemento das obrigações, ainda que essas regras fossem baseadas no modelo francês, a doutrina e a jurisprudência japonesas introduziram, num primeiro momento, os três tipos de inadimplemento das obrigações do direito alemão, isto é, mora (Verzug), impossibilidade (Unmöglichkeit) e adimplemento insuficiente (Schlechterfüllung), também conhecido como quebra positiva do contrato (Positive Vertragsverletzung). A doutrina e a jurisprudência

\footnotetext{
${ }^{21}$ MAKI - FUJIWARA, op. cit. (5), PP. 351 ss.

22 Veja SUZUKI, Die Entwicklung des japanischen Familienrechts unter dem Einfluß des europäischen Rechts, em ZvglRWiss 59 (1957), pp. 184 ss.

${ }^{23}$ MAKI - FUJIWARA, op. cit. (5), pp. 356 ss. Embora a entrada em vigor do código comercial de 1890 tivesse sido adiada até o fim de 1896, a parte sobre as sociedades, sobre as cambiais e sobre o cheque, assim como a sobre falência entraram em vigor em $1^{\circ}$ de julho de 1893 sob requerimento da indústria, sobretudo das Câmaras Comerciais. Os trabalhos legislativos pelo novo Código Comercial começaram em 1893, junto àqueles pelo Código Civil; porém, como o exame dos projetos não avançava por causa da situação política instável, também as partes remanescentes do Código Comercial de 1890 entraram em vigor em 1898. O novo Código Comercial elaborado nesse periodo foi promulgado em 09 de março de 1899 e entrou em vigor em 16 de junho do mesmo ano. MAKI - FUJIKAWA, op. cit. (5), pp. 369 ss.

${ }^{24}$ HOSHINO, op. cit. (13), pp. 208 ss.
} 
japonesas afastaram-se, porém, dessa classificação de proveniência alemã e falam de inadimplemento tout court ${ }^{25}$.

A parte sobre família e sucessões, que permaneceu em vigor até 1947 , baseava-se no "sistema das casas" japonês, isto é, o sistema de "ie" ("casa" no sentido abstrato) ${ }^{26}$, com exclusão da influência das legislações estrangeiras que se orientavam para o individualismo e o liberalismo. Segundo esse sistema das casas, o chefe da casa $(k o s h u)$, normalmente o pai, representava exteriormente a sua casa constituída por diversas gerações e tinha no interior da casa o poder de decidir os assuntos familiares. A posição do koshu competia por via sucessória - após a sua morte ou com a retirada da vida ativa - ao primogênito, com o seu patrimônio pessoal e o da casa (katoku-sôzoku); na ordem sucessória, o filho homem, natural ou adotado, precedia a filha mulher ${ }^{27}$. O registro do estado das pessoas era ordenado com base no chefe da casa e os membros da casa eram registrados conforme a relação com ele. $O$ matrimônio significava unir duas casas e ocorria, por isso, o consenso do chefe da casa $(k o s h u)^{28}$. O divórcio acontecia quase sempre (em 1940, 99,2\% dos divórcios) "consensualmente", em vez de judicialmente: divórcio "consensual" significava, nesse período, de fato, "repudiar a esposa", afastando-a da casa na qual era casada ${ }^{29}$. O fim de respeitar a ordem familiar correspondia à ideologia do governo meiji, que pretendia sustentar o Estado como uma família, em cujo topo se encontrava o imperador. O governo reintroduziu o pensamento do shintoismo, a religião japonesa, e a ideologia do confucionismo para fazer respeitar a hierarquia na família e na sociedade ${ }^{30}$.

De qualquer modo, com esse processo de codificação o Japão fundou um ordenamento jurídico completo e conseguiu, portanto, ab-rogar os tratados não paritários estipulados com os Estados ocidentais. O Japão sentia-se, pouco a pouco, orgulhosamente, como um dos Estados mais fortes do mundo, antes de perder a segunda guerra mundial.

${ }^{25}$ Veja KITAGAWA, Das Methodenproblem in der Dogmatik des japanischen und bürgerlichen Rechts, in AcP 166 (1966), pp. 330 ss.; ID., Drei Entwicklungsphasen im japanischen Zivilrecht, in Die Japanisierung des westlichen Rechts. Japanisch-deutsches Symposion in Tübingen vom 26. bis 28. Juli 1988, A CURA DI H. COING, HIRANO, KITAGAWA, etc., Tübingen 1988, pp. 125 ss. O artigo 415 do código civil japonês dispõe:

"Leistet der Schuldner nicht dem Inhalt der Schuld entsprechend, so kann der Gläubiger Schadensersatz verlangen. Dasselbe gilt, wenn die Leistung in Folge eines vom Schuldner zu vertretenen Umstandes unmöglich geworden ist". Veja MARUTSCHKE, op. cit. (4), pp. 156 ss. O artigo $415 \S 1$ do Código Civil japonês corresponde ao artigo 1218 do Código Civil italiano de 1942.

${ }^{26}$ SUZUKI afirma que o conceito de "ie" correspondia àquele de "gens", em vez daquele de "família" no direito romano. SUZUKI, op. cit. (21), p. 186.

${ }_{27}$ TANIGUCHI, Über das heutige japanische "Familien-System", in RabelsZ 10 (1936), pp. 484 ss.

${ }^{28}$ É de notar que também um matrimônio contraido sem o consenso do konshu era válido, se fosse inscrito no cadastro de família; o koshu, porém, poderia excluir quem havia contraído o matrimônio sem o seu consenso da casa e the tolher o direito de sucessão. TANIGUCHI, op. cit. (26), p. 480. ${ }^{29}$ MIZUNO, Grounds for Divorce in Japanese Law and Mechanisms of Divorce Payment Obligation, in Japanese Reports for the XIVth International Congress of Comparative Law (Athens, July $31^{\text {st }}-$ August $\left.6^{\text {th }} 1994\right)$, Tóquio 1995 , pp. 89 ss.

${ }^{30}$ Cfr. SUZUKI, op. cit. (21), pp. 186 ss. É de notar que a maior parte da população no período de edo era formada por camponeses, que tinham costumes diversos daqueles dos samurai. Por isso, 0 sistema das casas que foi disciplinado no Código Civil de 1898 não correspondia sempre à realidade e às exigências da sociedade inteira. Ibidem, pp. 194 ss.; veja também SUZUKI, Die Modernisierung des japanischen Familien - und Erbrechts, in RabelsZ 19 (1954), pp. 116 ss. 


\section{d) Depois da segunda guerra mundial}

Após a segunda guerra mundial, os Estados Unidos ocuparam o Japão e democratizaram e liberalizaram o nosso sistema social e econômico: por exemplo, foram liberados os consórcios monopolistas e foram divididos os bens imóveis dos grandes proprietários (latifundiários). Na reforma da Constituição Japonesa, a primeira questão foi essa: mantemos o imperador ou não? Os americanos pensavam que o imperador teria sido responsável pela segunda guerra mundial e, portanto, essa figura deveria ser eliminada. Entretanto, como não queriam destruir completamente a sociedade japonesa e tinham interesse em ser, no futuro, parceiros do Japão, que se situava numa posição estratégica do ponto de vista militar, ou seja, perto da Coréia e da China; ao fim, consentiram em manter o imperador. Em nossa Constituição, vigente desde 1947, o imperador tem o papel de "símbolo do Japão e da nação japonesa"31.

No campo do Direito Civil, o direito de família foi completamente modificado; o sistema da família patriarcal foi ab-rogado e o matrimônio foi considerado pela primeira vez como uma comunidade do homem e da mulher, tendo como base a paridade entre os sexos ${ }^{32}$. No direito comercial e econômico, a influência do direito americano foi marcante: por exemplo, o sistema do conselho de administração e do conselho fiscal das sociedades por ações seguiu o modelo dos Estados Unidos ${ }^{33}$. No conjunto, de qualquer modo, o ordenamento jurídico japonês continuava a ser orientado ao sistema romano-germânico, como anteriormente ${ }^{34}$.

2. As características do ordenamento jurídico japonês

Observando o ordenamento jurídico japonês, muitos estudiosos europeus, principalmente os comparatistas, como René David ${ }^{35}$, Zweigert e Kötz ${ }^{36}$, Sacco ${ }^{37}$, etc., acentuaram até hoje a função subsidiária do direito, isto é, a tendência de evitar os conflitos e a conservar a ordem social com instrumentos de conciliação e mediação e classificaram o sistema japonês junto ao chinês, coreano, etc. no "grupo do Extremo

${ }^{31}$ A Constituição foi promulgada em 03 de novembro de 1946 e entrou em vigor em 03 de maio de 1947.

32 Veja SUZUKI, op. cit. (29), pp. 110 ss. A lei de reforma foi promulgada em 22 de dezembro de 1947 e entrou em vigor em $1^{\circ}$ de janeiro de 1948.

${ }^{33}$ MAKI - FUJIWARA, op. cit. (5), p. 456.

${ }^{34}$ ODA, op. cit. (5), pp. 29 ss.

${ }^{35}$ RENÉ DAVID admite que existem grandes diferenças entre os Estados asiáticos como a China, o Japão, a Mongólia, a Coréia e os Estados da Indochina, mas afirma também que é possivel encontrar certas caracteristicas comuns entre esses paises, como por exemplo a função subsidiária do direito, a tendência de evitar os conflitos e a conservação da ordem social com instrumentos de conciliação e mediação. R. DAVID - C. JAUFFRET-SPINOSI, / grandi sistemi giuridici contemporanei, traduzido da $10^{a}$ edição (1992) por O. CALLIANO... [et al.] sob a direção de R. SACCO, Padova 1994, pp. 450 ss.

${ }^{36}$ ZWEIGERT e KÖTZ sustentavam até a segunda edição de seu livro "Introduzione al diritto comparato" a opinião segundo a qual o direito chinês e o japonês eram classificados no sistema juridico (Rechtskreis) do Extremo Oriente. K. ZWEIGERT - H. KÖTZ, Introduzione al diritto comparato, edição italiana organizada por A. DI MAJO e A. GAMBARO, vol. 1, Principi fondamentali, tradução de B. POZZO, Milão, 1992, pp. 359 ss.

37 Também SACCO fala do "direito do Extremo Oriente" no qual são incluidos a China e o Japão. GAMBARO - SACCO, op. cit. (1), pp. 505 ss. 
Oriente". Segundo a minha opinião, o ordenamento jurídico da China e o do Japão são muito diversos; a influência chinesa sobre o direito japonês limitou-se ao tempo antigo e, em particular, após a recepção dos códigos europeus no Japão, na Idade Moderna, não podemos identificar o nosso ordenamento jurídico com o chinês ${ }^{38}$.

Todavia, isso não significa que o nosso ordenamento jurídico tenha se tornado completamente europeu, pelo contrário, permanecem certas características japonesas na atuação do direito na sociedade. Muitos dentre os mesmos estudiosos japoneses chamam novamente a atenção sobre uma subdesenvolvida "consciência jurídica" (Rechtsbewußtsein) dos japoneses. Kawashima escrevia, em 1967, que a sociedade japonesa ainda era subdesenvolvida e pré-moderna, que os japoneses não estavam em condições de decidir entre o branco e o preto, e não faziam valer os seus direitos subjetivos. Por esse motivo, ainda havia uma ruptura entre "as leis recepcionadas da Europa" e "a consciência jurídica na sociedade japonesa". Somente com o passar do tempo os japoneses teriam se tornados conscientes do Direito e assim, aproximados da sociedade ocidental $^{39}$.

A essa tese se opõe Oki, sustentando que a consciência jurídica dos japoneses era suficientemente desenvolvida já no período edo porque havia muitas causas privadas; somente devido à falta de um sistema judiciário, os japoneses estavam habituados a resolver os conflitos entre eles, por via extrajudicial ${ }^{40}$. Murakami faz notar, porém, que na era de edo não era desenvolvida entre os governantes a idéia de garantir a tutela jurisdicional aos cidadãos para que fossem garantidos os seus direitos; nem também era imaginável para os cidadãos exigir do governo que os seus casos fossem examinados num processo justo. Na Europa, o 'conflito' era um estado ou uma situação normal e deviase sempre procurar resolver as controvérsias, julgando-as conforme a alternativa da "justiça" e da "injustiça", para defender o próprio Direito contra os outros. No Japão, ao contrário, a harmonia e a paz eram o estado normal, por isso o governo feudal paternalista protegia os membros da sociedade. Não era possível para nós desenvolver nos "cidadãos" uma consciência do tipo ocidental, isto é, que fossem cientes para 'sustentar' a sociedade, e ao mesmo tempo para poder exaltar os direitos quando necessário. Esse fenômeno japonês reflete, segundo Murakami, ainda hoje, a consciência jurídica subdesenvolvida dos japoneses ${ }^{41}$.

${ }^{38}$ Veja OKI, Hikakuhô kôgi, Tóquio 1992, pp. 117 ss.; MARUTSCHKE, op. cit. (4), p. 5; BAUM, Rechtsdenken, Rechtssystem und Rechtswirklichkeit in Japan - Rechtsvergleichung mit Japan -, in RabelsZ 59 (1995), pp. 259 ss. Na $3^{\text {a }}$ edição da obra de ZWEIGERT e KÖTZ, organizada por KÖTZ e publicada em 1996, não se menciona mais a classificação do sistema juridico do Extremo Oriente; mas o direito japonês e o direito chinês constituem ainda um único capítulo ("Recht im fernen Osten") e KÖTZ segue mais ou menos ainda a leitura tradicional, destacando a influência do confucionismo sobre a sociedade japonesa. K. ZWEIGERT - H. KÖTZ, Einführung in die Rechtsvergleichung, $3^{\text {a }}$ ed., Tübingen 1996, pp. 280 ss.

${ }^{39}$ KAWASHIMA, Nihonjiri no hôishiki, Tóquio 1967, pp. 5 ss.

${ }^{40}$ OKI, op. cit. (12), pp. 201 ss.

${ }^{41}$ MURAKAMi, op. cit. (8), pp. 11 ss.;

Io., Zur Struktur des japanischen Rechts, in ZjapanR 7 (1999), pp. 7 ss. Sobre a consciência juridica dos japoneses, veja-se a-monografia de RAHN, Rechtsdenken und Rechtsauffassung in Japan. Dargestellt an der Entwicklung der modernen japanischen Zivilrechtsmethodik, München, 1990. 
A diferença da Europa continental, onde o fundamento do sistema jurídico foi o direito romano, que se baseava nas normas privadas, no Japão, o Direito era antes de tudo fundado sobre o direito público, ou seja, sobre direito administrativo e penal. Aqui, o direito "emanado da autoridade" funciona em primeiro lugar como norma de decisão (Entscheidungsnorm), que era individualizada e aplicada somente após a emersão dos conflitos, em vez de funcionar como norma de conduta (Handlungsnorm), que garantisse a previsibilidade da solução dos conflitos e, nesse sentido, servisse para impedir a insurgência das controvérsias. Por exemplo, numa relação contratual os japoneses não fixam exatamente o direito e a obrigação das partes antecipadamente, mas preferem deixar espaço para resolver os problemas negociando e encontrando um compromisso; o direito intervém somente quando não é mais possível resolver os conflitos entre as partes ${ }^{42}$.

Após cem anos de experiência, o direito ocidental está colocando as raízes no Japão, mas num modo específico. Os europeus pasmam-se quando vêem como os juízes japoneses interpretam as normas legais livremente, sobretudo com base no "jori", que significa "ratio" ou "natureza das coisas" (Natur der Sache), e muito freqüentemente referem-se em seu juízo às cláusulas gerais como bona fides (art. 1 n. 2 do Código Civil Japonês ${ }^{43}$ ) ou buoni costumi (art. 90 do Código Civil Japonês ${ }^{44}$ ). Na Europa, os juízes têm a obrigação de garantir a previsibilidade e a estabilidade jurídica, enquanto no Japão os juízes recorrem amplamente à discricionariedade e não hesitam em se distanciar do texto das disposições para chegar ao resultado mais adequado e equilibrado. O Direito, como último meio ao qual se dirige para resolver os conflitos, é empregado mais livremente no Japão do que na Europa.

\footnotetext{
${ }_{42} \mathrm{Na}$ era meiji, após a recepção do sistema jurídico ocidental, havia uma norma no código de processo civil segundo a qual o juiz podia emitir um parecer vinculante para a conciliação. A estatística nos diz que de 1878 a 1885 cerca de 80 a $90 \%$ dos litígios nos tribunais de primeiro grau foram resolvidos através da conciliação. MARUTSCHKE, op. cit. (4), pp. $40 \mathrm{ss}$. Também hoje, a importância da solução dos conflitos pela conciliação é ressaltada.

43 Veja Art. 242 BGB (Die Erfordernis der Leistung nach Treu und Glauben).

${ }^{44}$ Veja Art. 138 Abs. 1 BGB (Die Nichtigkeit eines Rechtsgeschäfts, das gegen die guten Sitten verstößt).
} 